\title{
The etiology of febrile illnesses among febrile patients attending Felegeselam Health Center, Northwest Ethiopia
}

\author{
Hailu Tadesse ${ }^{1, *}$, Kebede Tadesse ${ }^{2}$ \\ ${ }^{1}$ Department of Microbiology, Immunology and Parasitology; College of Medicine and Health Science, Bahir Dar University, Bahir Dar, \\ Ethiopia \\ ${ }^{2}$ Department of Microbiology, Immunology and Parasitology; School of Medicine, Addis Ababa University, Addis Ababa, Ethiopia
}

\section{Email address:}

tadessehailu89@yahoo.com (H. Tadesse),tkas2003@gmail.com (K. Tadesse)

\section{To cite the article:}

Hailu Tadesse, Kebede Tadesse. The Etiology of Febrile Illnesses among Febrile Patients Attending Felegeselam Health Center, Northwest Ethiopia. American Journal of Biomedical and Life Sciences. Vol. 1, No. 3, 2013, pp. 58-63. doi: $10.11648 /$ j.ajbls.20130103.14

\begin{abstract}
The causes of acute febrile illness remain undifferentiated in many parts of the world and their burden is still challenging particularly in resource poor countries. The problem is significance especially in malaria endemic areas of tropical and sub-tropical regions. A cross sectional study was conducted during December 2011 in Northwest Ethiopia to determine the etiological agents of febrile illnesses among 398 acute febrile patients. Vein blood was collected to determine the etiological agents of febrile illnesses. The analysis of generated data revealed that the prevalence of malaria, typhoid, typhus and relapsing fever were $51.5 \%, 10.3 \%, 5 \%$ and $0 \%$, respectively. Malaria prevalence found to be the highest among other febrile illnesses followed by typhoid and typhus. Of the malaria infections Plasmodium falciparum prevalence accounts the highest $49.75 \%$ followed by Plasmodium vivax $1.75 \%(n=398)$. Awareness of the community about the sign and symptom of febrile illnesses were less. In addition, Proper bed net utilization was lower in rural than urban. Therefore, it is important to perform parasitological examination and serological tests simultaneously to encourage proper diagnosis and treatment of acute febrile cases especially in malaria endemic areas.
\end{abstract}

Keywords: Malaria, Febrile Illness, Prevalence, Awareness

\section{Introduction}

An acute febrile illness (AFI) is a type of illness characterized by a sudden onset of increased body temperature to a level above the normal [1]. The causes of febrile illnesses remain poorly characterized in many parts of the world. Limited resources and the great diversity of AFI etiologies in tropical regions challenge diagnosis, treatments, and public health responses to endemic and epidemic diseases [2]. Furthermore majority of the patients have non-descript symptoms and usually no focal point of infection. Health care providers lacking proper diagnostic tools are usually unable to determine specific etiologies, often diagnosing patients presumptively based on clinical features and assumptions regarding circulating pathogens [3].

AFI of unknown origin is a common clinical syndrome among patients seeking hospital care [4]. Malaria, acute bacterial infections such as pneumonia, typhoid, typhus and relapsing fever are the major causes of morbidity and mortality in resource poor countries. Since AFIs have similar sign and symptoms, diagnosis and management of malaria and other causes of fever remains challenging [5]. A failure of properly treating febrile conditions is frequent. False positive malaria microscopy result is common and microscopic confirmation of malaria is often unavailable or unreliable. Treating AFIs only for malaria without parasitological examination in malaria endemic areas leads to mistreatment and unrecognized deaths [6].

In most areas of Ethiopia, health institutions do not provide full laboratory services to diagnose AFIs. In those areas treatment of febrile conditions especially in children is usually based on clinical symptoms and guidelines such as the Integrated Management of Childhood Illness (IMCI). IMCI combines prevention and treatments of common childhood illnesses such as pneumonia, malaria, measle, 
diarrhea and under nutrition [7]. These illnesses are non specific and have similar sign and symptom especially during the early stage of the onset [8]. Managing of fever with antimalarial drug using general guide lines in first level health facilities and communities is common [9].

The use of IMCI guidelines without laboratory confirmation for AFI which have common sign and symptoms has lead to high levels of over-diagnosis and misuse of drugs. A major challenge in case management of AFIs is that the disease typically presents with non-specific symptoms. It is difficult to distinguish by sign and symptoms. Both under diagnosis and over-diagnosis might be occurred during case managements [10]. These drain resources at the household level and mostly affecting the poorest families [11]. Improving the accuracy of diagnosis is expected to reduce extra expenses of cases and reduce unrecognized deaths.

\section{Material and Methods}

\subsection{Study Population}

A cross sectional study was conducted from acute febrile patients aged greater than one year (living in Pawe Special Woreda) who attend Felegeselam Health Center in December 2011. The area is located at a distance of $570 \mathrm{~km}$ Northwest of Addis Ababa. The area has an elevation of about $1000-1050 \mathrm{~m}$ above sea level and malaria transmission takes place throughout the year. The study subjects engaged in this study were 398 febrile patients, clinically suspected for malaria, who visited outpatient department (OPD) of the Health Center. Eligible study subjects for the study were those patients with acute febrile illness (body temperature $>37.5^{\circ} \mathrm{c}$ ) or a history of fever for the last two weeks. Children with acute febrile illness less than one year, individuals who took antimalarial or antibiotic drugs within two weeks before blood test and who refused to participate were excluded.

\subsection{Clinical and Laboratory Diagnosis}

Training was given for health staffs prior to data collection. Trained health staffs took anthropometric measurements, recorded the common symptoms associated with febrile illnesses, and performed standard clinical examination after obtaining clinical written consent from the study participants. By using available information, they made diagnosis including socio-demographic information, present and past history of febrile patients, environmental related factors, laboratory data and treatments.

Blood specimen 2 to $5 \mathrm{ml}$ of venous blood was collected by vein puncture from each febrile cases to do blood film, rapid diagnostic test (RDT), widal and weil felix tests. The presence of malaria was checked in all febrile patients by microscopy and RDT. Thick and thin blood films were done from three drops and one drop (one drop $=20 \mu \mathrm{l}$ ) of blood, respectively. In thick film preparation, the blood was distributed over an area of $1 \mathrm{~cm}^{2}$ and air dried. The thin smear was air dried and fixed with methanol alcohol. Staining of the thick and thin films was done using $6 \%$ Giemsa stain solution for 10 minutes. The slides were washed and air dried. Identification of plasmodium and detection of Borellia were done on the thick film. Species identification of malaria was done on the thin film preparation $[12,13]$.

A three-band CareStart ${ }^{\mathrm{TM}}$ RDT test kits were used as means of diagnosis for malaria according to the directions of the manufacturer. It is RDT targeting HRP-2 and pan pLDH. The quality of package and the expiry date was checked before use. Fresh blood sample of $5 \mu 1$ was transferred directly to the sample pad by the provided sample applicator. All CareStart ${ }^{\mathrm{TM}}$ malaria tests were labeled with patient ID number and results recorded 20 minutes after adding 2 drops $(60 \mu \mathrm{l})$ of clearing buffer. The presence of a unique HRP-2 line indicates an infection with $\mathrm{P}$. falciparum, whereas a unique pan $\mathrm{pLDH}$ line is found in infection with one or more of the non-falciparum species. The presence of both HRP-2 and pan-pLDH lines indicates an infection with $P$. falciparum or a mixed infection with P. falciparum and one or more of the nonfalciparum species. A test result without a control line was considered invalid. The invalid tests were retested and the number of invalid tests was recorded [14].

Widal (Spinreacty - Linear chemicals S.L.) and Weil felix (Cromatest- linear chemicals S. L.) agglutination tests were introduced as a serologic technique to aid in diagnosis of typhoid fever and Reckettisae, respectively. The widal test was done based on demonstrating the presence or absence of antibody against antigens of Salmonella typhi in the serum of an infected patient by using Tydal antigen (flagellar(H) and somatic(O) ) [15]. Weil felix test was done to determine the presence of Rickettisa based on the principle that some strains of proteus share common somatic constituents (progen OX-19 antigen) with certain species of Rickettisae.

\subsection{Statistical Methods}

Data were entered in to excel and transported to SPSS. Analysis was performed by SPSS version 16 statistical software package. Frequency and percentage were calculated for the study variable. Chi-square, $\mathrm{p}$ value and two tail Fisher's exact tests were used to calculate and determine significance. In all statistical tests, the differences were considered to be statistically significant if p-value less than 0.05 .

\subsection{Ethical Consideration}

The department ethical review committee of Microbiology, Immunology and Parasitology, College of Health Science, Addis Ababa University approved the project. The health staffs and researchers obtained informed consents from patients, and parents or guardians. Patients tested positive malaria or other AFIs diseases were treated accordingly. AFI patients who were tested negative for 
malaria, typhoid, typhus and relapsing fever were managed based on the decision of the clinician.

\section{Result}

A total of 398 acute febrile cases attended Felegeselam Health Centre were enrolled in this study. The mean age of the attendants was 18.5 years with a standard deviation (SD) of 12.9 ranging from 1-70. There were more females than males with a sex ratio of male to female of 0.79 . The sign and symptoms most frequently reported by acute febrile illnesses in this study were headache, fever, joint pain, loss of appetite, vomiting, and general weakness.

The prevalence of malaria, typhoid, typhus and relapsing fever were $51.5 \%, 10.3 \%, 5 \%$ and $0 \%$, respectively (Table 1). However, it was small in number; infection with two or three causative agents was common in this study. Among the 41 cases of typhoid, 21 cases were co-infected with malaria. Similarly, out of the 20 cases of typhus, 4 cases were co-infected with malaria. There were also 6 cases found to be co-infected with typhoid and typhus. Only one case was infected with three causative agents (malaria, typhoid and typhus). Out of the total cases $2.5 \%$ of the patients were infected with more than one pathogen and $60.6 \%$ of the cases were infected at list by one pathogen. The rest $39.4 \%$ negative cases most likely had other causes. Relapsing fever was examined by thick blood film microscopy but all the cases were negative probably the area is not an endemic area.

All the attendants were asked whether they had trends using locally available antimalarial drugs or not. The result indicated that $(12.1 \%)$ of AFI cases responded that they treated themselves by sign and symptoms without laboratory diagnosis.

Malaria was examined with a golden standard thick blood film Microscopy in all attendants. The result revealed that prevalence of malaria $(50.5 \%)$ was found to be the most prevalent disease among AFIs. Of which $P$. falciparum and P. vivax accounted over $49 . \%$ and $1.5 \%$, respectively. Malaria was found to be the most prevalent disease among AFIs. On the other hand P. falciparem contributed to $97 \%$ of the malaria infections and the rest $3 . \%$ was due to $P$. vivax $(n=205)$. No mixed infection was reported during the study time. The prevalence of malaria was greater in females $(52.7 \%)(\mathrm{n}=222)$ than males $(50 \%)$ $(\mathrm{n}=176)$. However, the difference was not statistically significant $\left(\chi^{2}=0.221, \mathrm{P}=0.896\right)$ (Table 1$)$. There were six AFI pregnant cases during the study period.

Similarly by Carestart ${ }^{\mathrm{TM}}$ method, $205(51.5 \%)$ of the 398 patients tested were positive for malaria parasites. Among 205 people with malaria, $97.1 \%$ of the cases were infected with P. falciparum and the rest $2.9 \%$ was infected with P.vivax as detected by CareStart ${ }^{\mathrm{TM}}$.

Table 1. Percentage distribution of febrile cases according to their age group, sex and address in Northwestern Ethiopia, December 2011[n (\%)]

\begin{tabular}{|c|c|c|c|c|c|c|c|c|}
\hline & & $\begin{array}{c}\text { Number } \\
\text { of } \\
\text { Cases (n) }\end{array}$ & $\begin{array}{c}\text { P.falciparum } \\
\text { n (\%) }\end{array}$ & $\begin{array}{c}\text { P.vivax } \\
\text { n (\%) }\end{array}$ & $\begin{array}{c}\text { Total malaria } \\
\text { pos n (\%) }\end{array}$ & $\begin{array}{c}\text { Typhoid } \\
\text { n (\%) }\end{array}$ & $\begin{array}{c}\text { Typhus } \\
\text { n (\%) }\end{array}$ & $\begin{array}{c}\text { Relapsing } \\
\text { fever } n \\
(\%)\end{array}$ \\
\hline \multirow[t]{3}{*}{ Age } & $1-4$ & 52 & $23(44.2)$ & $1(1.9)$ & $24(46.2)$ & $0(0)$ & $1(1.9)$ & $0(0)$ \\
\hline & $5-17$ & 167 & $88(52.7)$ & $3(1.8)$ & $91(54.5)$ & $16(9.6)$ & $9(5.4)$ & $0(0)$ \\
\hline & $\geq 18$ & 179 & 87 (48.6) & $3(1.7)$ & $90(50.3)$ & $25(13.96)$ & 19 (10.6) & $0(0)$ \\
\hline \multirow[t]{2}{*}{ Sex } & M & 176 & $85(48.3)$ & $3(1.7)$ & $88(50)$ & $14(7.9)$ & $10(5.7)$ & $0(0)$ \\
\hline & $\mathrm{F}$ & 222 & $113(50.9)$ & $4(1.8)$ & $117(52.7)$ & $27(12.2)$ & $10(4.5)$ & $0(0)$ \\
\hline \multirow[t]{3}{*}{ Address } & Urban & 358 & $181(50.6)$ & $7(1.96)$ & $196(54.7)$ & 38 (10.6) & $18(5)$ & $0(0)$ \\
\hline & Rural & 60 & $17(28)$ & $0(0)$ & $17(28)$ & $3(5)$ & $2(3.3)$ & $0(0)$ \\
\hline & Total & 398 & $198(49.6)$ & $7(1.8)$ & $205(51.5)$ & $41(10.3)$ & $20(5)$ & $0(0)$ \\
\hline
\end{tabular}

$*_{\mathrm{n}}=$ Number, $\mathrm{P}=$ Plasmodium, $\mathrm{pos}=$ positive

Utilization of insecticide treated bed nets within the community plays a great role in prevention of malaria transmission both in urban and rural setups. The presence and proper utilization of the bed net was assessed on the 398 attendants in the study area. All the bed nets were insecticide treated bed nets and donated freely from the Pawe Special Woreda Ministry of Health. All (100\%) attendants had responded "yes" for presence of insecticide treated bed net. Of which $(85.4 \%)$ were properly used insecticide treated bed nets but the rest $(14.6 \%)$ did not use the insecticide treated bed net properly $(n=398)$. This is statistically significant $\left(\chi^{2}=18.44, \mathrm{P}<0.001\right)$ (Table 2$)$. On the other hand, proper use of bed net is important in malaria prevention. The proper utilization of insecticide treated bed net was different between urban and rural attendants. Proper bed net usage was higher dweller in urban $(87.2 \%)(\mathrm{n}=358)$ than in the rural $(70 \%)(\mathrm{n}=40)$. This was statistically significant $\left(\chi^{2}=9.68, \mathrm{P}<0.001\right)$ (Table 2). The chance of properly utilization of bed net in urban was $3.5\left(\chi^{2}=17.813, \mathrm{P}=0.000, \mathrm{OR}=3.488,95 \%\right.$ confidence interval $(\mathrm{CI})=1.877-6.480)$ times higher than individuals in rural. 
Table 2. Percentage distribution of proper bed net utilization of febrile cases in relative to their addresses in Northwestern Ethiopia, December 2011 [n $(\%)]$

\begin{tabular}{|c|c|c|c|c|c|c|}
\hline \multirow[b]{2}{*}{$\begin{array}{l}\text { Proper Bed net } \\
\text { utilization }\end{array}$} & \multicolumn{2}{|c|}{ Urban } & \multicolumn{2}{|c|}{ Rural } & \multirow{2}{*}{$\begin{array}{l}\text { Total } \\
\text { n (\%) }\end{array}$} & \multirow[t]{2}{*}{$\mathbf{X}^{2}, \mathbf{p}$} \\
\hline & $\begin{array}{c}\text { Malaria Positive } \\
\text { n (\%) }\end{array}$ & $\begin{array}{c}\text { Malaria } \\
\text { Negative } \\
\text { n (\%) } \\
\end{array}$ & $\begin{array}{c}\text { Malaria Positive } \\
\text { n (\%) }\end{array}$ & $\begin{array}{c}\text { Malaria } \\
\text { Negative } \\
\text { n (\%) } \\
\end{array}$ & & \\
\hline Yes & $147(41.1)$ & $162(45.3)$ & $11(27.5)$ & $16(40)$ & $336(84.4)$ & \\
\hline \multirow[t]{2}{*}{ Total } & 41 (11.5) & $8(2.2)$ & $6(15)$ & 7 (17.5) & $62(15.6)$ & $18.44,<0.001$ \\
\hline & $188(52.5)$ & $170(47.5)$ & $17(42.5)$ & $23(57.5)$ & 398 & \\
\hline $\mathrm{X}^{2}, \mathrm{P}$ & \multicolumn{6}{|c|}{$9.68,<0.001$} \\
\hline
\end{tabular}

* Mal Pos $=$ Malaria Positive, Mal Neg= malaria Negative, $\mathrm{n}=$ number

\section{Discussion}

AFI is the most common causes of morbidity and mortality in tropical and subtropical countries. Infections with AFI agents cause unrecognized deaths in malaria endemic areas. The present study revealed that AFI infections were prevalent in Pawe Special Woreda, Northwestern Ethiopia. The most common causes of AFI infection was malaria followed by typhoid and typhus. A similar result was obtained in a study conducted at four health institutions, in West Gojjam [8].

People who live in most malarious areas are familiar with the clinical manifestations of malaria and most malaria patients visit the nearest health facilities [16]. Similarly the people in the Pawe Special Woreda have limited knowledge about the sign and symptoms of other AFIs like typhoid and typhus. Though they had good awareness about clinical symptoms and treatments of malaria, they treated themselves outside the health institution by antimalarial drugs without laboratory confirmation. This finding indicates that the rise a need to strengthen creating awareness on the clinical manifestation of AFI and treatment seeking behavior of the community through health education.

Based on the data collected, all the study participants had at list one bed net per household; however (84.4\%) cases utilized the bed net properly. This is found to be comparable with previous report $81.6 \%$ malaria prone areas of Ethiopia [17] but this finding is higher than $66 \%$ in malaria endemic area of Ethiopia [13] and 68.8\% in Southern Ethiopia [18].

The most important consequence of treating only malaria when no parasitemia exists is failure to address other life threatening conditions like typhoid and typhus. Lack of awareness about the sign and symptoms of the people, limitation of the serological tests and high cost of test for the poor forced some AFI patients to be treated with locally available antimalaria drugs. As a result patients may be exposed for over diagnosis, misdiagnosis and misuse of drugs which are a universal phenomenon in many African countries where severe malaria was common [6]. In the present study $12.1 \%$ AFI cases responded that they took locally available antimalarial drugs without laboratory confirmation. This is consistence with a previous report $16 \%$ of the febrile cases treated themselves from previous history and without laboratory diagnosis in an area of seasonal malaria transmission in rural Ethiopia [19].

Even though serological tests for typhoid and typhus give false positive result, they are relatively cheap, easy to perform, rapid and needs minimal training [15]. These tests were not used consistently in Felegeseelam Health Center due to scarcity of the test kits and unaffordable payment for widal and weil felix tests by poor patients. Direct serological agglutination of widal and weil felix tests were done in this study to diagnosis typhoid fever and typhus, respectively. The prevalence of typhoid $(10.6 \%)$ identified in this study was comparable with $8 \%$ in South India [20], relatively higher from the previous $(5.8 \%)$ reported in west Gojjam [8] and 1.6\% in Bahir Dar town [21] but lower than the previous (32.1\%) reported in Cameron [22] and (18\%) in Egypt [4]. While, the prevalence of typhus (5.3\%) obtained in the present study was consistent with (5.1\%) reported from West Gojjam [8].

Multiple infections were evident from the present observation of malaria and typhoid, malaria and typhus, and typhoid and typhus. Similar multiple infections were also obtained in a previous study conducted on febrile illness of different etiology among out patients in west Gojjam [8]. The present finding $2.5 \%$ of the patients were infected with more than one pathogen was comparable with previous 3.5\% reported from South Central Cambodia [23].

The similarities in the clinical manifestation of acute febrile illnesses of different causative agents suggest the need to evaluate disease specific interventions. A major challenge in malaria case management among AFI patients in the present study was the disease typically presents with non-specific symptoms. This was in agreement with a previous study which indicated malaria has indistinguishable manifestation from those of several other febrile illnesses common in malaria endemic area [24].

In the present study prevalence of malaria $(50.5 \%)$ was relatively high. This finding is somehow similar with previous reports $(62 \%)$ in West Gojjam [8] and (66.2\%) at Dore Bafeno Health Centre in Southern Ethiopia [25]. 
Prevalence of P. falciparum (49\%) observed in the present study was significantly high. The present report is comparable with earlier findings (54.3\%) at Dore Bafeno health centre in southern Ethiopia [25], (47.3\%) in west Gojjam [8] but somehow higher than (30.5\%) at Upper Volta region of Ghana [26].

According to the present study the prevalence of malaria in females $(52.7 \%)$ was greater than males $(49.4 \%)$ though there was no significant difference by sex. Comparable malaria prevalence results $(67.2 \%)$ females and $(65.3 \%)$ males in Dore Bafeno health centre [25] and (30\%) females and $(25 \%)$ males were reported at village level in areas with unstable malaria transmission in Ethiopia [28].

Even though the prevalence of malaria was not statistically significant among age groups $\left(\mathrm{X}^{2}=0.406, \mathrm{P}=\right.$ $0.982)$, its prevalence $(46.2 \%)$ was relatively higher among under five children. This result is in agreement with the finding of other researchers $(50.3 \%)$ in Uganda [19], $(42.1 \%)$ in Tanzania [29] and (30.5\%) in Upper Volta region of Ghana [26].

The prevalence of malaria (53.4\%) among students in this study was high A similar relatively high prevalence of malaria $(47 \%)$ in Nandi but lower prevalence of malaria $(23 \%)$ in Bondo was reported previously in two sites in Kenya among school age children [30]. In the present study high prevalence of malaria among students was recorded since all the students were AFI patients. Generally, in proper bed net utilization, staying or sleeping outside home during at night, watching games at night and irrigation practices in the study area were probably the possible reasons why prevalence of malaria was high in the present study.

\section{Conclusion}

This study reveals that Limited resources and the great diversity of AFI etiologies in tropical regions challenge diagnosis and treatment of patients. There is however, no single test that can guarantee reliable results for different febrile illnesses, hence the need for perform parasitological examination and serological tests simultaneously to encourage proper diagnosis and treatment of acute febrile cases especially in malaria endemic areas.

The strength of this paper was diagnosis febrile cases using both parasitological examination and serological tests simultaneously. However, not including culture for salmonella infection and using serological tests which have low specificity were the limitations of this study. The quality might be improved if culture was included.

\section{Acknowledgements}

The authors greatly acknowledge Addis Ababa University School of Graduate studies for its financial support to conduct this research. The Pawe special woreda health office, Felegeselam Health Center and Minjar
Shenkora woreda health office who support different reagents are also highly acknowledge. Finally we would like to thank administrative and health staffs of Felegeselam Health Center and the study participants.

\section{Reference}

[1] Archibald L.K, Reller L.B, "Clinical microbiology in developing countries”, Emerg Infect Dissease, vol. 7, pp.302-305, 2001.

[2] Black R.E, Morris S.S, Bryce J. "Where and why are 10 million children dying every year?", The lancet, vol.361, pp. 2226-2234, 2003.

[3] Kasper M.R, Blair P.J, Touch S, Sokhal B, Yasuda C.Y, Williams M, Richards AL, Burgess T.H, Thomas WF, Putnam S.D, "Infectious Etiologies of Acute Febrile Illness among Patients Seeking Health Care in South Central Cambodia", Am. J. Trop. Med. Hygiene, vol. 86, pp. 246253, 2012.

[4] Afifi S.K.E, Azab M.A, Youssef F.G, Sakka H.E, Wasfy M, Mansour H, Said O, Magda R, Francis M, "Hospital-based surveillance for acute febrile illness in Egypt: a focus on community-acquired bloodstream infections", Am J. Trop. Med. Hygiene, vol. 73, pp. 392-399, 2005.

[5] Lubell Y, "Likely Health Outcomes for Untreated Acute Febrile Illness in the Tropics in Decision and Economic Models: A Delphi Survey”, PLoS one, vol. 6(2), 2011.

[6] Gwer S, Newton C.R.J.C, Berkley J.A, “Over-diagnosis and co-morbidity of severe malaria in African children: a Guide for Clinicians", Am. J. Trop. Med. Hygiene, 77, pp 6-13, 2007.

[7] Reyburn H, Mbakilwa H, Mwangi R, Mwerinde O, Olomi R, Drakeley C, Whitty C.J, "Rapid diagnostic tests compared with malaria microscopy for guiding outpatient treatment of febrile illness in Tanzania: randomised trial”, BMJ, vol. 334, pp. 403, 2007.

[8] Animut A, Mekonnen A, Shimelis D, Epheraim A, "Febrile illness of different etiology among out patients in four health centers south western Ethiopia", JPN. journal of infect. Dissease, vol. 62, pp. 107-110, 2009.

[9] Schellenberg A, Adam J.R.M, Mshinda T, Masanja H, Kabadi H, Mukasa G, John O, Charles T, Nathan S, Wilczynska R, Mgalula K, Mbuya L, Mswia C, Manzi R, Savigny F.D.E, Schellenberg D.D, Victora C, "Effectiveness and cost of facility-based Integrated Management of Child Illness (IMCI) in Tanzania" Lancet; vol. 364, pp. 1583-1594, 2004.

[10] Koram K.A, Emolyneux M, "When Is "Malaria" Malaria? The Different Burdens of Malaria Infection, Malaria Disease and Malaria-Like Illnesses". Am. J. Trop. Med. Hygiene, vol. 77, pp. 1-5, 2007

[11] Meara O.W.P, Nkesa J.M, Steketee R, Greenwood B, "Changes in the burden of malaria in sub-Saharan Africa" Lancet Infect Disease, vol. 10, pp. 545-555, 2010.

[12] MOH: Malaria diagnosis and treatment guidelines for health workers in Ethiopia, 2nd edition: Federal Democratic 
republic of Ethiopia 2005. [URL: cnhde.ei.columbia.edu/files/1/1/2005]

[13] MOH: National malaria guide line 3rd edition, National malaria guide line-MOH. [URL: www.moh.gov.et/.../National/malaria/guidelines/2012]

[14] Maltha J, Gillet P, Bottieau E, Cnops L, Esbroeck MV, et al, "Evaluation of a rapid diagnostic test (CareStart"M Malaria HRP-2/pLDH (Pf/pan) Combo Test) for the diagnosis of malaria in a reference setting", Malaria Journal, vol. 9, pp. $171,2010$.

[15] Aftab R, Khurshid R, "Widal agglutination titer: a rapid serological diagnosis of typhoid fever in developing countries". Pak. J. Physiology, vol. 5, 65-76, 2009.

[16] Deressa W, Chibsa S, Olana D, "Treatment Seeking of Malaria Patients in East Shewa Zone of Oromia, Ethiopia" Ethiop. J. Health Development, vol.17, pp. 9-15, 2003.

[17] Animut A, Gebre-Michael T, Medhin G, Balkew M, Bashaye S, Seyoum A, "Assessment of distribution, knowledge and utilization of insecticide treated nets in selected malaria prone areas of Ethiopia”, Ethio. J. Health Development, vol. 22, pp. 22, 268-274. 2008.

[18] Dagne G, Deressa W, "Knowledge and utilization of insecticide treated mosquito nets among freely supplied households in Wonago Woreda, Southern Ethiopia”, Ethiop. J. Health Development, vol. 22, pp. 34-41, 2008.

[19] Deressa W, "Treatment-seeking behavior for febrile illness in an area of seasonal malaria transmission in rural Ethiopia”, Malaria Journal, vol. 6 pp. 49, 2007.

[20] Chrispal A, Boorugu H, Gopinath K.G, Chandy S, Prakash J.A.J, Thomas E.M, Abraham A.M, Abraham O.C, "Thomas K: Acute undifferentiated febrile illness in adult hospitalized patients: the disease spectrum and diagnostic predictors: an experience from a tertiary care hospital in South India", Trop. Doctor, vol. 40, pp. 230-234, 2010.

[21] Abera B, Biadegelgen F, Bezabih B, "Prevalence of Salmonella typhi and intestinal parasites among food handlers in Bahir Dar Town, Northwest Ethiopia", Ethiop. J. Health Development, vol. 24, pp. 46-50, .2010.

[22] Ndip L.M, Bouyer D.H, Travassos D.A, Rosa P.A, Titanji V.P.K, Tesh R.B, Walker D.H, "Acute spotted fever
Rickettsiosis among Febrile Patients, Cameroon", Emer. Infect. Disease, vol. 10, pp. 432-437, 2004.

[23] Kasper M.R, Blair P.J, Touch S, Sokhal B, Yasuda C.Y, Williams M, Richards A.L, Burgess T.H, Wierzba T.F, Putnam S.D, "Infectious Etiologies of Acute Febrile Illness among Patients Seeking Health Care in South-Central Cambodia", Am . J. Trop. Med. Hygiene, vol. 86, pp. 246$253,2012$.

[24] Kachur P, Schulden J, Goodman C.A, Kassala H, Farida B.E, Khatib R.A, Causer L.M, Mkikima S, Abdulla S, Bloland P.B, "Prevalence of malaria parasitemia among clients seeking treatment for fever or malaria at drug stores in rural Tanzania 2004", Trop. Med. and International Health. Vol.11, pp. $441-451,2006$.

[25] Zerihun T, Degarege A, Erko B, “Association of ABO blood group and Plasmodium falciparum malaria in Dore Bafeno Area, Southern Ethiopia", Asian Pacific Journal of Tropical Biomedicine, vol. 1, pp. 289-294, 2011.

[26] Chuks J.M, Irene K.A, "Prevalence and Management of Malaria in Ghana: A Case Study of Volta Region", African Population Studies, vol. 22(1), 2003

[27] Ashley E.A, Touab M, Ahrer M, Hutagalung R, Htun K, Luchavez J, Dureza C, Proux S, Leimanis M, Lwin M.M, Koscalova A, Comte E, Hamade P, Page A-L.N, Guerin P.J, "Evaluation of three parasite lactate dehydrogenase based rapid diagnostic tests for the diagnosis of falciparum and vivax malaria”, Malaria Journal, vol. 8, pp. 241, 2009.

[28] Asnakew K.Y, Sucharita G, Afework T.H, Dereje O.D, Hrishikesh, P.P, "Spatial analysis of malaria incidence at the village level in areas with unstable transmission in Ethiopia", Int. J. H. Geographics, vol. 8, pp. 5, 2009.

[29] Kachur P, Schulden J, Goodman C.A, Kassala H, Farida B.E, Khatib R.A, Causer L.M, Mkikima S, Abdulla S, Bloland P.B, "Prevalence of malaria parasitemia among clients seeking treatment for fever or malaria at drug stores in rural Tanzania 2004", Tropical Medicine and International Health, vol. 11, pp. 441-451, 2006.

[30] Clarke S, Brooker S, Kiambo J, Njau N, Estambale E.B, Muchiri E, Magnussen P, "Malaria morbidity among school children living in two areas of contrasting transmission in western Kenya", Am. J. Trop. Med. Hygiene, vol. 71 pp. 732-738, 2004. 